\title{
Contrast threshold of random dot stereograms in anisometropic amblyopia: a clinical investigation
}

\author{
I. C. J. WOOD, J. A. FOX, AND M. G. STEPHENSON
}

From the Department of Ophthalmic Optics, University of Manchester Institute of Science and Technology, and Manchester Royal Eye Hospital, Oxford Road, Manchester

SUMMARY The contrast thresholds of random dot stereograms were obtained for both anisometropic amblyopic and normal patients.

The elevation of the contrast threshold found in both amblyopic and non-amblyopic eyes of the anisometropes reflects the relative strength of the binocular inhibition mechanism present. These findings were related to the standard clinical tests used in this investigation and other recent psychophysical and physiological investigations.

Amblyopia, to quote Von Noorden, is an abnormal binocular interaction. Yet very few psychophysical experiments have in fact done anything to elucidate or quantify this abnormal interaction. A survey of the literature reveals that most of the studies were carried out monocularly and tested the light sense in terms of either absolute threshold or the differential threshold using brightness matching. As a consequence it has been shown that the absolute threshold appears to be normal and the differential threshold appears to be slightly elevated in the amblyopic eye under photopic conditions. Interestingly enough, when Miller (1954) then Grosvenor (1954) and later Lawill and Burian (1966) investigated monocular threshold contrasts of small gratings, an elevation of the contrast threshold was revealed in the amblyopic eye.

But the importance of the monocular findings has been somewhat overstated, for recent studies concerned with binocular interaction have shown a far more profound inhibition of the general visual characteristics of the amblyopic eye when the sound eye is in use. Stimulation of the sound eye activates an increase of the luminance threshold (Flynn et al., 1971), reduces the visual acuity (Pugh, 1954; Awaya and Von Noorden, 1971), and increases the size and depth of the suppression scotoma in the amblyopic eye (Markensen, 1959; Pratt-Johnson, 1969).

The area of the binocular extinction phenomenon induced by retinal rivalry is greater in the amblyopic patient/subject than in the normal observer (Aulhorn,

Address for reprints: Mr I. C. J. Wood, Department of Ophthalmic Optics, UMIST, PO Box 88, Manchester M60 1QD
1967; Aulhorn et al., 1969). All these experiments therefore have disclosed the presence of a binocular inhibition mechanism in functional amblyopia but have failed to quantify it.

It was decided to use random dot stereograms in combination with contrast threshold to try and quantify the amount of inhibition present in amblyopia. Random dot stereograms were used because they test stereoscopic vision without the added requirement of form recognition. This particular type of stimulus must involve cortical interaction, since it is known that disparity detectors in monkeys do not occur before area 18 of the visual cortex. Contrast threshold was used as the variable testing parameter as it is generally agreed that it is the most sensitive of psychophysical parameters.

It can be assumed that the amount of contrast required to obtain a threshold measurement is a reflection of the signal output from any given number of neurons and is probably related to the number of neurons firing at any given time. If the contrast threshold is reduced, it can be reasonably assumed that it reflects a reduced output either through a reduced number of cells firing or through the inhibition of these cells. Thus by using the following methods we set out to investigate the binocular inhibition mechanism which appears to occur in all types of functional amblyopia, i.e. microstrabismic and anisometropic amblyopia.

\section{Methods}

\section{CLINICAL EXAMINATION}

The following clinical tests were carried out on all patients: Visual acuity with linear visual acuity 

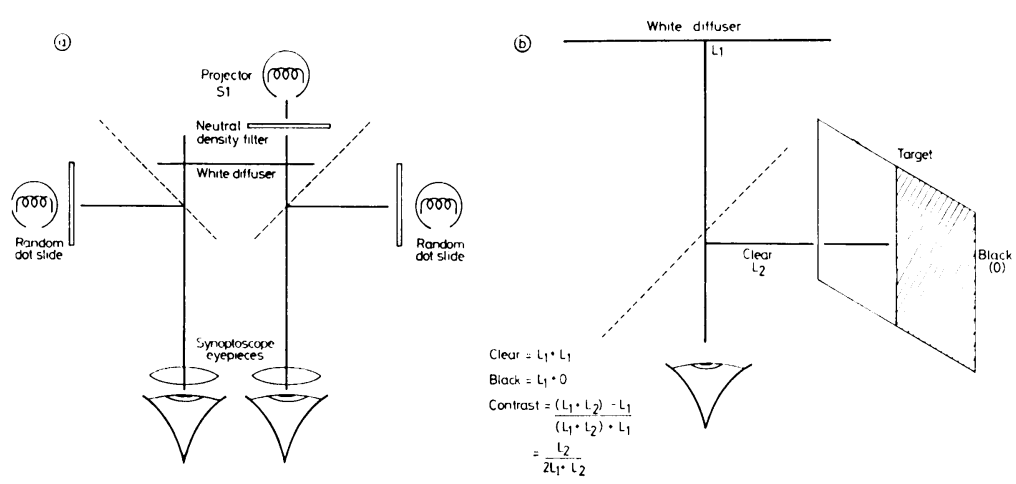

Fig. 1a Diagram of the synoptoscope apparatus showing the light paths and the relative positions of the random dot slides, the projector $S 1$, and the neutral density filter N1. Note that projector S1 illuminated only the white diffuser in front of the eye being tested for contrast threshold

Fig. $1 b$ The relative contrast of synoptophore random dot target is given by the relative level of luminance of the black dot divided by the relative level of luminance from the clear background. Therefore the contrast $=L_{2} / 2 L_{1}+L_{2}$ chart 0.33 and $6 \mathrm{~m}$; cover test; the $4 \Delta$ prism test; the projectoscope; the TNO and Wirt stereotest.

\section{NORMAL SUBJECTS}

The criterion for the selection of normal subjects was as follows: No obvious pre-existing eye condition; no amblyopia; no anisometropia; bifoveal fusion.

\section{ANISOMETROPES}

The criterion for the selection of anisometropic amblyopes was as follows: Anisometropia of $1 \mathrm{D}$ or more; patients who were co-operative; patients who had previously demonstrated stereoscopic vision - this included 6 'microstrabismic' patients, i.e., patients who in effect have binocular stereo vision (BSV), although a microstrabismus is in fact present.

\section{Contrast threshold examination}

For the first experiment a synotoscope was used in conjunction with some prepared random dot slides; the angular subtense of these slides was 1000 seconds of arc. These were viewed with the Stanworth Synoptoscope eyepieces in place. This allowed retroillumination of 1 of the stereo slides to take place. The eye not under test observed the other stereo slide through the other eyepiece. Now the light from S1 was varied by changing a neutral density filter at N1 (as shown in Fig. 1a). The change in luminance thereby affected on the white diffusing screen changed the contrast of the slide. The contrast was calculated as shown in Fig. $1 b$.

For the second experimental study the random dot patterns were printed on Polaroid vectograph film, the two halves of the stereogram being mutually polarised" at right-angles to each other. Thus a change in polarisation, and hence the contrast of one of the halves of the stereogram, was brought about by rotating a Polaroid filter. The relationship between the angle of the Polaroid and the amount of contrast displayed is shown in Fig. 2. The thickened line shows the relationship between the contrast obtained from the random dot stereogram and the angle through which the Polaroid filter has moved as measured by a microdensitometer. The dotted line on the graph shows the calculated contrast. The Polaroid filter was placed in front of the observer's eyes by a trial frame. The test was held at $40 \mathrm{~cm}$ from the observer's eyes, and in common with the previous experimental study the angular subtense of the random dot stereograms was a 1000 seconds of arc.

In both experimental situations the observer was presented with the stereograms in the null position, so that the eye under test was not given sufficient contrast information to enable the stereo image to be seen. The contrast in each case was then slowly increased until the observer became aware of depth (low frequencies) and shape (high frequencies) of the disparate object hidden in the random dot pattern. Previous training of the subjects was carried out to familiarise all subjects with the experimental arrangements.

\section{Results}

The graph in Fig. $2 a$ concerns the near test and shows contrast as the ordinate and the angle through which the Polaroid is moved as the abscissa. As denoted by the arrows, the contrast thresholds of both amblyopic and sound eye are substantially raised when compared with the normal observer ( $t$ diff $=2.30, \quad \mathrm{P}<0.05)$. This is true for both anisometropic and microstrabismic amblyopes. Similar findings are shown in Fig. $2 b(t$ diff $=4.03$, $\mathbf{P}<0.01$ ). The ordinate is relative contrast and the abscissa expresses the amount of neutral density filter required.

Noticeable is the asymmetry of the thresholds in 


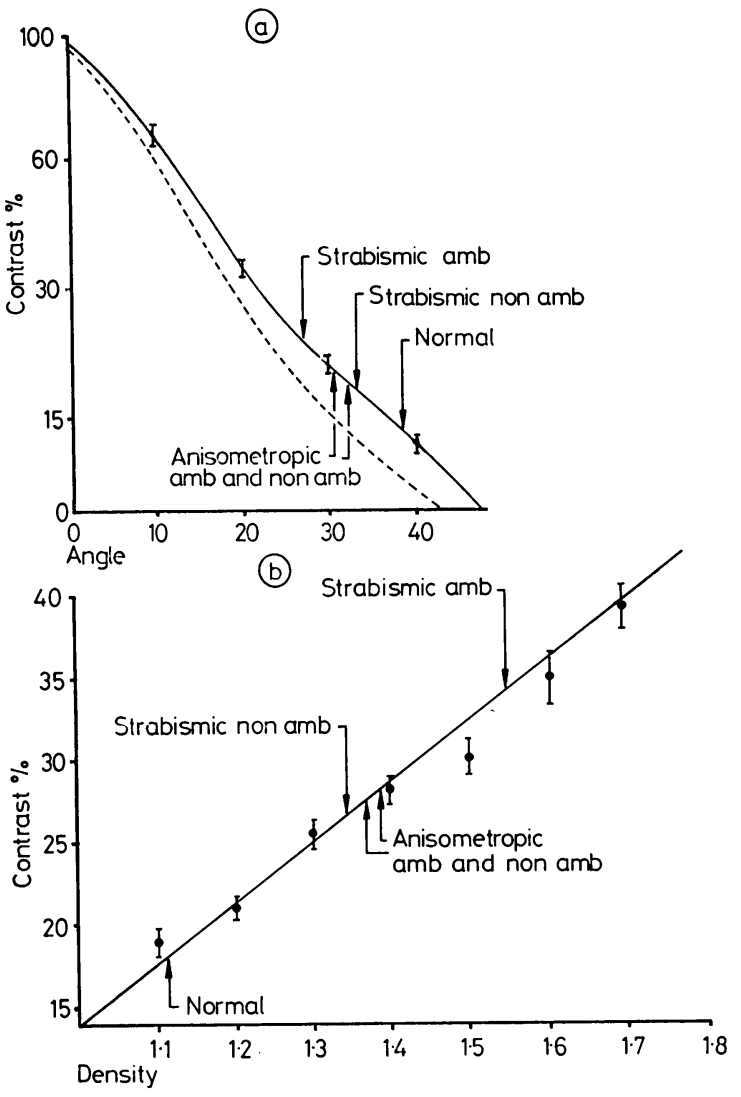

Fig. 2 The relative mean contrast thresholds obtained by polarisation technique (upper graph) by a change in luminance (lower graph) for 6 microstrabismic amblyopes, 14 anisometropic amblyopes, and 10 normal patients, as indicated by arrows. The dotted line in the upper graph is the calculated relative contrast: the thick line is the relative contrast as measured by microdensitometer. The error bars on each graph show the standard deviation of each measurement taken

functional amblyopia, the contrast thresholds for the amblyopic eye being higher $(t \operatorname{diff}=2 \cdot 25$, $\mathbf{P}<0.05)$ than that of the normal eye in both anisometropic and microstrabismic amblyopia. As probably expected, the 6 subjects who had a detectable deviation by cover test had a greater asymmetry of the contrast threshold as well as a higher contrast threshold in the amblyopic eye ( $t$ diff $=3 \cdot 56, \mathrm{P}<0.05)$.

Table 1 summarises the mean contrast thresholds found for each group of subjects. However, to throw a spanner in the works, Table 2 shows 4 subjects who showed that the contrast threshold in the non-amblyopic eye was higher than the amblyopic eye.
To pursue the idea of binocular inhibition a little further, both microstrabismic and anisometropic amblyopes were further classified into 2 groupsthose giving a positive 4-dioptre prism test (i.e., indicating presence of a small central suppression scotoma) and those giving a negative 4-dioptre prism test.

As can be seen from Fig. $3 a, b$, the positive 4dioptre prism test gave a higher threshold in the amblyopic eye. This is much as expected, for if the suppression scotoma is identified by the 4-dioptre prism test its presence should make itself felt.

We also explored the relationship between fixation and the depth of the binocular inhibition mechanism. Table 3 shows us that the contrast threshold is higher for parafoveal fixation than that obtained for central fixation.

During a pilot study it had been noted that the recognition of depth and recognition of shape did not simultaneously occur when random dot stereograms were presented to amblyopic subjects. This points to the fact that the contrast threshold for low spatial frequencies is higher than that for high spatial frequencies. When these contrast thresholds were analysed, it was found there was a very high correlation between the contrast threshold for the

Table 1

\begin{tabular}{|c|c|c|c|}
\hline \multirow[b]{3}{*}{$\begin{array}{l}\text { Subject/cye } \\
\text { classification }\end{array}$} & \multirow[b]{3}{*}{$\begin{array}{l}\text { No. of } \\
\text { 'yes }\end{array}$} & \multicolumn{2}{|c|}{ Contrast threshold } \\
\hline & & \multicolumn{2}{|l|}{ Mean per cent } \\
\hline & & $\begin{array}{l}\text { Near random } \\
\text { dot test }\end{array}$ & $\begin{array}{l}\text { Distance random } \\
\text { dot test }\end{array}$ \\
\hline Normal & 20 & 14 & 19 \\
\hline Strabismic amblyopi: & 6 & 23 & 33 \\
\hline Strabismiz non-amblyopi z & 6 & 17 & 27 \\
\hline Anisonctropic amblyopi: & 14 & 21 & 28 \\
\hline $\begin{array}{l}\text { Anisometropic non- } \\
\text { amblyopi: }\end{array}$ & 14 & 19 & 28 \\
\hline
\end{tabular}

Table 2

\begin{tabular}{|c|c|c|c|c|}
\hline \multirow{4}{*}{ Patient } & \multicolumn{4}{|c|}{ Contrast threshold } \\
\hline & \multicolumn{4}{|c|}{ Mean per cent } \\
\hline & \multicolumn{2}{|c|}{ Near random dot test } & \multicolumn{2}{|c|}{ Distance random dot test } \\
\hline & Amblyopic & Non-amblyopic & Amblyopic & Non-amblyopic \\
\hline 1 & 17 & 40 & 35 & 45 \\
\hline 2 & 14 & 35 & 25 & 29 \\
\hline 3 & 17 & 35 & 29 & 33 \\
\hline 4 & 21 & 40 & 35 & 45 \\
\hline
\end{tabular}


(a)
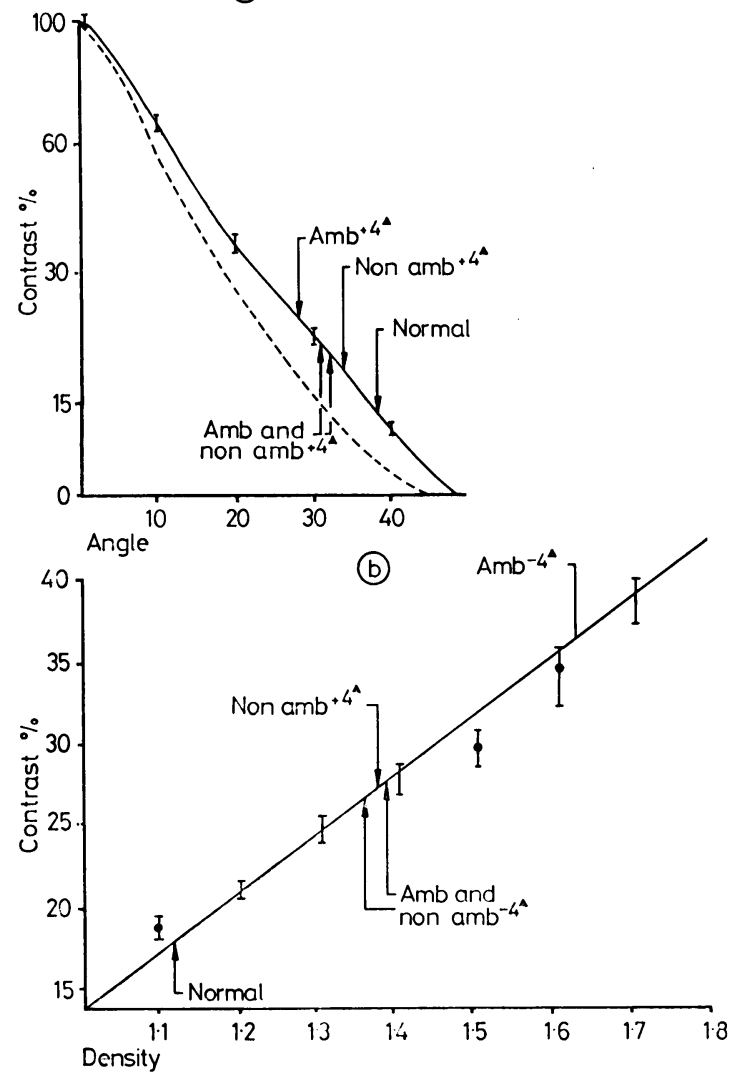

Fig. 3 The relative mean contrast thresholds for 20 anisometropic amblyopes, 10 of whom gave a positive response to the $4 \Delta$ prism test

detection of high frequencies (shape) and the visual acuity obtained. This correlation was $-0 \cdot 75$. If the elevation of contrast threshold reflects the amount of binocular inhibition present in amblyopia, this last result indicates there is a strong linear relationship between the loss of visual acuity and the increase in the strength of the binocular inhibition mechanism. However, the correlation found for the loss of visual acuity versus the contrast threshold for low spatial frequencies was lower at $-0 \cdot 5$.

\section{Discussion}

\section{PHYSIOLOGICAL IMPLICATION}

Our findings complement previous investigations concerned with abnormal binocular interaction in amblyopia by showing that there is a marked elevation of the contrast threshold of both sound and amblyopic eye under binocular testing conditions when compared with the normal observer.
Table 3 Contrast threshold per cent

\begin{tabular}{|c|c|c|c|c|c|}
\hline \multicolumn{3}{|c|}{$\begin{array}{l}\text { Foveal fixation } \\
\text { NRDS } \quad \text { DRDS }\end{array}$} & \multicolumn{3}{|c|}{$\begin{array}{l}\text { Parafoveal fixation } \\
\text { NRDS DRDS }\end{array}$} \\
\hline $\begin{array}{l}\text { Range } \\
\text { Mean }\end{array}$ & $\begin{array}{l}0-20 \\
12 \cdot 8\end{array}$ & $\begin{array}{l}0-75 \\
3 \cdot 5\end{array}$ & & $\begin{array}{l}0-35 \\
18 \cdot 5\end{array}$ & $\begin{array}{l}7 \cdot 5-41 \\
13\end{array}$ \\
\hline \multicolumn{3}{|c|}{$\begin{array}{l}\text { Correlation coefficient of high spatial } \\
\text { frequency or 'shape' contrast threshold } \\
v s \text { visual acuity }\end{array}$} & & -0.75 & \\
\hline \multicolumn{3}{|c|}{$\begin{array}{l}\text { Correlation coefficient of low spatial } \\
\text { frequency or 'disparity' contrast } \\
\text { threshold } v s \text { visual acuity }\end{array}$} & $=$ & -0.5 & \\
\hline
\end{tabular}

Usually the elevation of the contrast threshold is greater in the amblyopic eye, but several cases have shown that the non-amblyopic eye is sometimes greater than the amblyopic eye. This emphasises the fact that there is an abnormal binocular interaction, since if amblyopia were purely a monocular phenomenon we would expect an elevation of the contrast threshold in the amblyopic eye alone. The elevation of the contrast threshold also appears to be greater in the presence of microstrabismus or parafoveal fixation when the relative alignment of the 2 fovea is poor. Both these findings suggested that the mechanism of amblyopia is due to a reduction in the number of binocular cells functioning either through binocular inhibition mechanism or through cell loss.

Recent investigation of induced amblyopia in cats suggest that there is no actual cell loss (Eggers and Blakemore, 1977) but that the number of binocularly driven cells of the visual cortex are dominated by the input of the normal eye. When the input of the amblyopic eye was monocularly driven, a lower contrast sensitivity was found. A preference for low spatial frequency and for cut-off to be lower in the amblyopic or defocused eye was characteristic of the small number of binocular cells found.

Similarly, our study has shown that the high spatial frequencies, as denoted by the shape of the hidden 3D figure in the stereogram, have a much higher threshold than the low spatial frequencies. This indicates that the binocular high frequency analysers or cells are inhibited in amblyopia. The low spatial frequency analysers or cells on the other hand binocularly summate. This finding is further complemented by the recent psychophysical investigations of Levi and Harwerth (1977), who suggest that the ' $X$ ' sustained pathway is inhibited in amblyopia whereas the ' $Y$ ' transient pathway appears to be normal.

CLINICAL IMPLICATIONS

Having developed a method for binocularly 
screening patients which utilises contrast threshold and random dot stereopsis, we can now determine the amount of binocular inhibition present for high and low spatial frequencies in amblyopia. It is hoped that binocular frequency response will give some indication of the likely outcome of treatment of amblyopia. At Manchester Royal Eye Hospital we are undertaking further work to investigate the effects of treatment on contrast threshold and frequency response in amblyopia.

\section{References}

Aulhorn, E. (1967). Die gegensietige Beemfussing Abbildungsleisher Netz haustellen bei normalen und gestortem Binocularsehen. Documenta Ophthalmologica, 23, 26-61.

Aulhorn, E., Eisert, S., and Hanns, H. (1969). Die Beemfussing der binocularen Helligkeitsempfinding durch die sensoriche Pravalenz. Documenta Ophthalmologica, 26, 230-239.

Awaya, S., and Von Noorden, G. K. (1971). Visual Acuity of Amblyopic Eyes under Monocular and Binocular conditions: further observations. In Orthoptics: Proceedings of the II International Orthoptic Congress, Amsterdam, 1971, Ed. J. Mein, J. J. M. Bierlaagh, and T. E. A.
Brummel Kamp-Dons, p. 146. Excerpta Medica: Amsterdam.

Eggers, H. M., and Blakemore, C. (1977). Physiological basis of anisometropic amblyopia. In press.

Flynn, J. T., McKenney, S. G., and Dannheim, E. (1971). Brightness matching in strabismic amblyopia. American Orthoptic Journal, 21, 38-48.

Grosvenor, T. (1954). The effect of duration and background luminance upon brightness discrimination of an amblyope. American Journal of Optometry and Archives of American Academy of Optometry, 34, 639-663.

Lawill, T., and Burian, H. M. (1966). Luminance, contrast function and visual acuity in functional amblyopia. American Journal of Ophthalmology, 62, 511-520.

Levi, D. M., and Harwerth, R. S. (1977). Spatio-temporal interactions in anisometropic and strabismic amblyopia. Investigative Ophthalmology, 16, 90-94.

Markenson, G. (1959). Monocular und binocular statische Perimetrie zur Untersuchung der Hemmungsvorgange beim Schielen. Albrecht von Graefes Archiv für klinische und experimentelle Ophthalmologie, 160, 573-587.

Miller, E. F. (1954). The nature and cause of impaired vision in the amblyopic eye of a squinter. American Journal of Optometry and Archives of American Academy of Optometry, 32, 615-623.

Pratt-Johnson, J. A. (1969). Sensory phenomenon associated with suppression. British Orthoptic Journal, 26, 15-24.

Pugh, M. (1954). Foveal vision in amblyopia. British Journal of Ophthalmology, 38, 321-331. 